\title{
MicroscopyPioneers
}

\section{Pioneers in Optics: William Hyde Wollaston}

\section{Eric Clark}

From the website Molecular Expressions created by the late Michael Davidson and now maintained by Eric Clark, National Magnetic Field Laboratory, Florida State University, Tallahassee, FL 32306

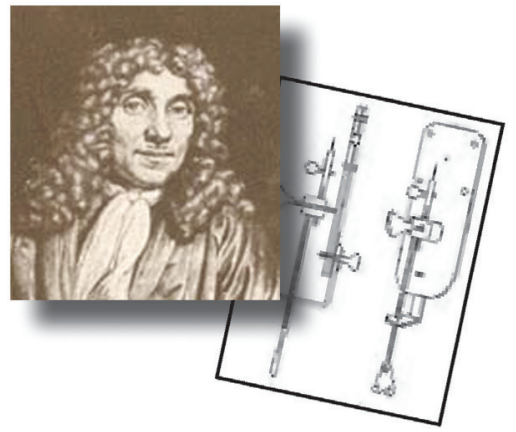

eclark@magnet.fsu.edu

\section{William Hyde Wollaston \\ (1766-1828)}

The quantity and diversity of William Hyde Wollaston's research made him one of the most influential scientists of his time. Although formally trained as a physician, Wollaston studied and made advances in many scientific fields, including chemistry, physics, botany, crystallography, optics, astronomy, and mineralogy. He is particularly noted for being the first to observe dark lines in the spectrum of the sun, discovering the elements palladium and rhodium, and proving the elementary nature of niobium and titanium. Wollaston also developed a method for making platinum metal malleable, establishing equivalence between galvanic and frictional electricity, and originating several inventions in optics.

Wollaston was born in Norfolk, England on August 6, 1766 to a vicar, Francis Wollaston, and Althea Hyde. He received his formal education at Charterhouse School and the Gonville and Caius Colleges of Cambridge University. He graduated with a degree in medicine and was immediately elected a member of the Royal Society and an associate of the French Academy of Sciences. After practicing as a physician for seven years, he abandoned the field to move to London and focus solely on his research interests. A recipient of the Copley medal in 1802, Wollaston became secretary of the Royal Society in 1806 and served as president from 1820-1828. He lived alone, meticulously conducting his investigations until he died of a brain tumor on December 22, 1828. He donated most of the profits made from his discoveries to scientific societies for further research purposes. The mineral Wollastonite was named in honor of his many achievements.

Wollaston initially became renowned in physiology. In 1797, he described the main components of urinary calculi. Ironically, the future optical pioneer's eyesight soon began failing and, when he suddenly gave up his medical practice in 1800 , he became an associate of Humphry Davy at the Royal Institute. While working with Davy in 1809, he described a vibratory action of muscular activity. In 1812, he identified a new type of bladder stone that he named cystic oxide, later called cystine, the first known amino acid. Twelve years later Wollaston provided the best contemporary physiological description of the ear.

Wollaston formed another alliance to perform chemistry studies and experiments, this time with Smithson Tennant. Platinum had long evaded the efforts of chemists to concentrate and purify the precious element, and the pair decided to join in the endeavor. When Tennant first tried to produce platinum, the result was his discovery of the new elements iridium and osmium. Wollaston's later attempt led him to the discovery of palladium and rhodium. He then invented the technique of powder metallurgy and produced malleable platinum in 1805. The feat proved extremely profitable and provided him with financial independence for the rest of his life. He waited until 1828, however, to reveal the description of his secret process to the Royal Society.

Wollaston made great strides in various disciplines of physics. In 1802, he developed the refractometer, an instrument for determining refractive index. The device helped Wollaston verify the laws of double refraction in Iceland spar, on which he wrote a treatise. Also in 1802, Wollaston discovered that the sun's spectrum is not a continuous gradient, but is interrupted by a number of dark lines. Joseph Fraunhofer made the same observation and precisely described the phenomenon twelve years later. In 1807, Wollaston developed a version of the camera lucida, which would eventually lead to Fox Talbot's discoveries in photography.

The camera lucida largely consisted of a four-sided prism, the Wollaston prism, that has since proved indispensable in microscopic work. A Wollaston prism is composed of two geometrically identical wedges of quartz or calcite (which are birefringent, or doubly refracting materials) cut in a way that their optical axes are oriented perpendicular when they are cemented together to form the prism. If a linear polarizer is oriented so that plane-polarized light enters the prism at a 45-degree angle with respect to the optical axes of the two birefringent prism halves, the light is sheared into two plane-polarized components that are oriented mutually perpendicular to each other. The invention was originally used as a drawing aid that allowed artists to draw outlines in proper perspective. A piece of paper was laid flat on a drawing board, and the artist would look through a lens mounted on a small stand that contained the prism. The observer's eye was placed so that the pupil was half covered by the horizontal face of the prism, allowing him to see both the paper and a faint image of the subject, which he could then easily trace. Although the device 
was awkward to use, it made artistic renderings significantly simpler to produce and quickly grew in popularity.

The Wollaston prism is fundamentally important to interferometry and differential interference contrast (DIC) microscopy. DIC is an excellent mechanism for rendering contrast in transparent specimens. It is a beam-shearing interference system in which the reference beam is sheared by a minuscule amount, generally somewhat less than the diameter of an Airy disk. The technique produces a monochromatic shadow-cast image that effectively displays the gradient of optical paths for both high and low spatial frequencies present in the specimen. Those regions of the specimen where the optical paths increase along a reference direction appear brighter (or darker), whereas regions where the path differences decrease appear in reverse contrast. As the gradient of optical path difference grows steeper, image contrast is dramatically increased.

As a skilled optician, Wollaston created a doublet lens consisting of two plano-convex lenses with their flat surfaces facing the object plane. This important lens design was refined by Charles Chevalier in 1830 and later perfected by Joseph J. Lister as a high-resolution achromatic lens. In 1829, the doublet lenses, as well as the simple microscope that employed them, were described posthumously. That same year Wollaston's description of a single-lens condenser used to funnel light into a microscope with increased intensity, improving the overall resolution, was also published. Many compound microscopes used Wollaston's system although he did not live to see them, and until recently, microprojectors employed a virtually identical construction.

MT

\section{Microscope Temperature Control}

- Precise temperature control at the sample; in the FOV

- Fits in the slide holder

\section{- No microscope modifications}

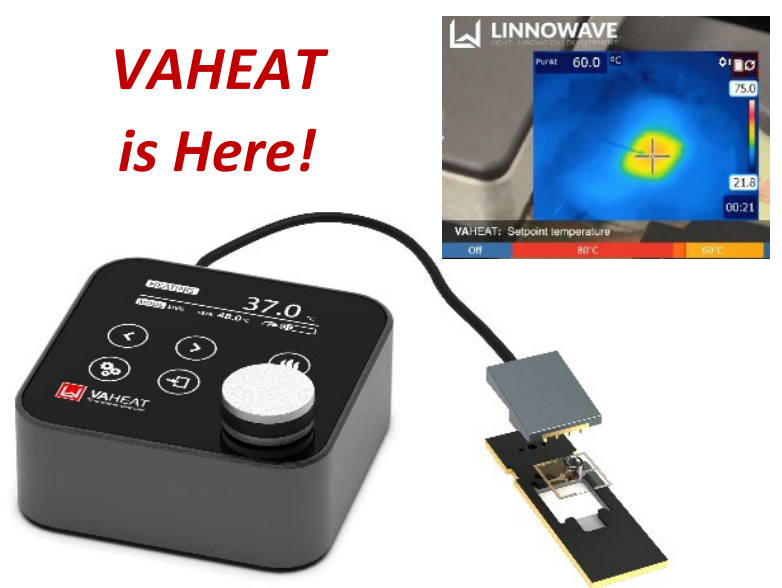

BostonElectronics

www.boselec.com | vaheat@boselec.com

\section{MEO Engineering Company, Inc.}

High Technology on a Small Scale since 2004

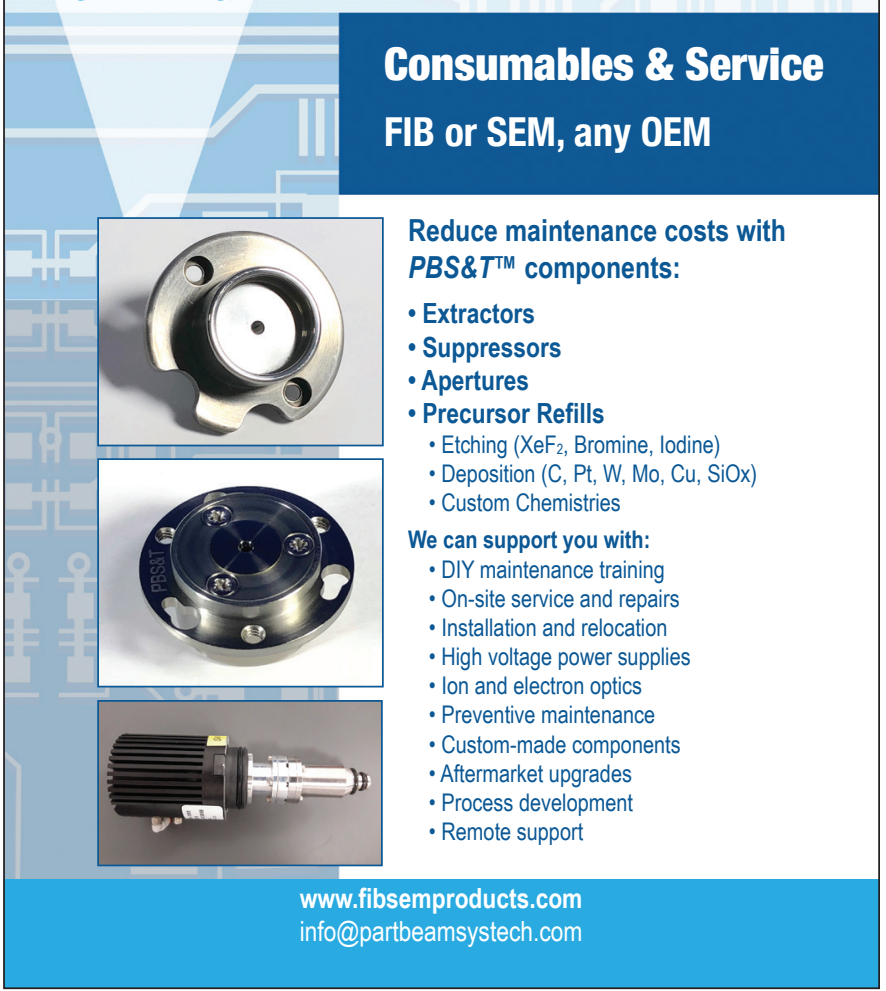

\section{MEO Engineering Company, Inc.}

High Technology on a Small Scale since 2004

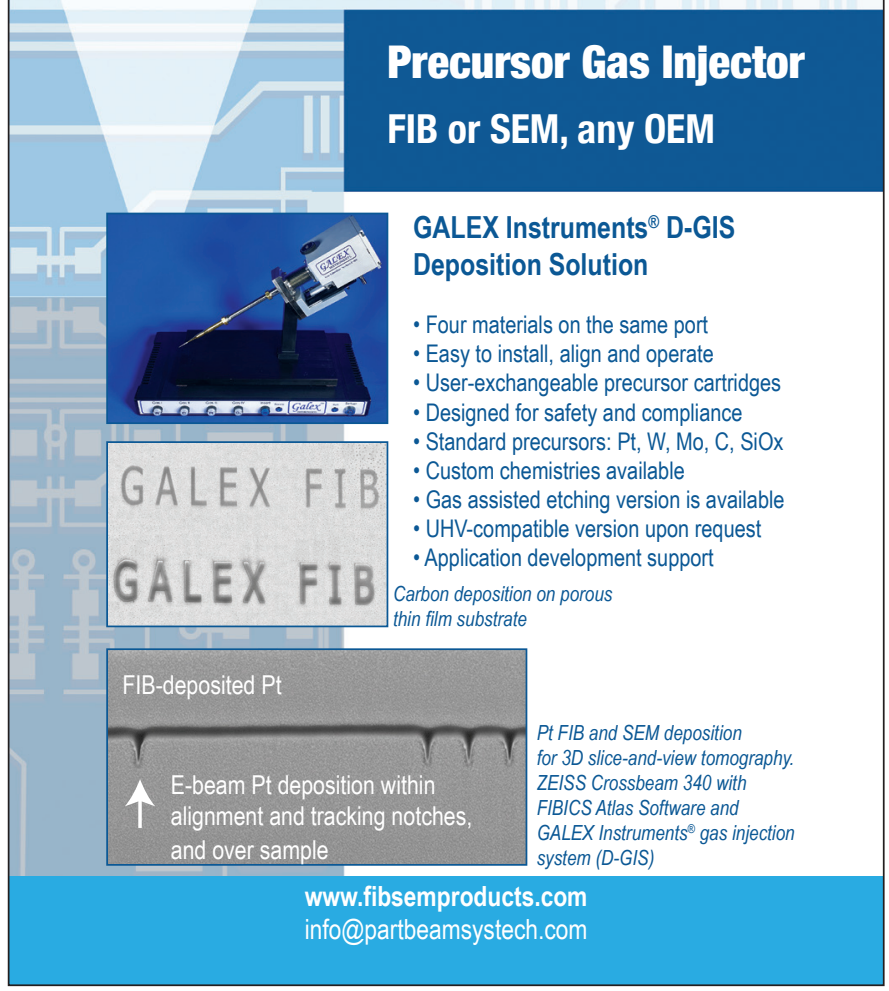

